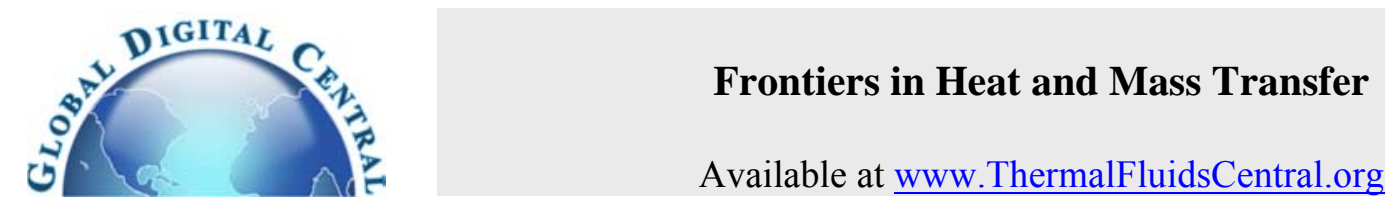

\title{
FLOW AND HEAT TRANSFER OF CARBON NANOFLUIDS OVER A VERTICAL PLATE
}

\author{
Mahantesh M Nandeppanavar ${ }^{a, *}$, S. Shakunthala \\ ${ }^{a}$ Department of studies and Research in Mathematics, Govt. College Kalaburagi-585105, India \\ ${ }^{b}$ Department of studies and Research in Mathematics, Gulbarga University, Kalaburagi-585106, India
}

\begin{abstract}
In this paper, the buoyancy effect on flow and heat transfer characteristics of nanofluid in presence of carbon nanotubes due to a vertical plate is investigated. The obtained nonlinear PDE's are converted to the non-linear ordinary differential equations by applying the similarity transformations corresponding to the boundary conditions. These boundary value problems are solved numerically using fourth order Runge-kutta method together with the efficient shooting iteration scheme. The nature of the flow and heat transfer are plotted and discussed in detail. It is noticed that buoyancy effect is very useful in cooling the system and present results compared with previously published result, our results are in very good agreement for some limiting cases. In the result buoyancy and prandlt number has the same effects.

Keywords: Boundary Layer, Heat Transfer, Vertical Plate, Grashof Number, Nano-Fluids, Carbon Nanotubes, Numerical Solution.
\end{abstract}

\section{INTRODUCTION}

As we know the buoyancy is the upward force exerted by a fluid and opposes the weight of an immersed object. The object density is greater than that of the fluid in which it is submerged tends to sink. If the object is either less dense than the liquid or is shaped approximately, the force can keep the object a float. For example, if you drop wood into water, buoyancy will keep it afloat, likewise boat, balloon etc. In the buoyancy clearly we can find the mechanisms that the fluid motion generated naturally like a pump, fan, suction devices etc but also one more thing we observe that the variation in density of the fluid due to temperature gradient. (Wang et al. 2007 ) studied the characteristics of natural convection and they used water with alumina $\left(\mathrm{Al}_{2} \mathrm{O}_{3}\right.$ nanofluids) theoretically, along with this, they investigated Jang and Choi's for predicting the effective thermal conductivity of nanofluids, Akbarinia and Behzadmehr (2007) concentrated on laminar mixed convection of nanofluids with water as a base fluid and aluminium $\left(\mathrm{Al}_{2} \mathrm{O}_{3}\right)$ in horizontal curved tube studied in three dimensions, they discussed the effects of buoyancy force, centrifugal force and nanoparticle concentration and plotted studied their characteristics. Corcione (2010) investigated the effects of buoyancy heat transfer nanofluids are analysed theoretically. We can see that nanofluid which acts as a single phase fluid rather than a conventional solid liquid mixture which signifies that all convective heat transfer correlations feasible for single phase flows can be stretched out to nanoparticles suspensions implies that thermo physical properties appearing in them are the nanofluid effective properties evaluated at the reference temperature.

Makinde and Aziz (2011) concentrated on boundary layer flow this is propagated in a nanofluid due to linearly stretching sheet. They used numerical method and obtained equations shown that are effects on Brownian motion and thermophoresis. The different thermal conditions of constant temperature or constant heat flux are employed for convective heating boundary condition. In the solution part they noticed, the temperature and nanoparticle concentration distributions depend upon the five parameters those are prandlt number Pr number
Le, the Brownian motion parameter $\mathrm{Nb}$, thermophoresis parameter $\mathrm{Nt}$ and convection biot number $\mathrm{Bi}$ and by employing the numerical methods they solve the governing equations to found the solutions and plotted graphs for various physical parameters and discussed, as other parameters fixed the local concentration of nanoparticles increases as the convection biot number increases but decreases as the Lewis number increases. The authors (Nasrin et al., 2012) analysed heat transfer and fluid flow of natural convection with $\mathrm{Al}_{2} \mathrm{O}_{3}$ - water nanofluid studied in a vertical closed chamber. Here the authors used numerical method with finite element technique with Galerkin's weighted residual simulation. They examined the parameters such as nanoparticle volume fraction $\phi$, prandlt number $\operatorname{Pr}$ and cavity aspect ratio are due to the presence of nanoparticle the heat transfer effects are identified and based on this effects the results are pointed as ,by decreasing the prandlt number amplifying the effects of nanoparticles due to increased effective thermal diffusivity and a correlation is matured graphically for the average nusselt number as a function of the cavity aspect ratio.

In present situation authors are very much interested doing research in nanofluids, as they can be found in computers, games consoles, mobile phones, blue-ray players, TVs as well as cars, planes and medical technology likewise the authors Njane and Makinde (2013) are studied the effect of magnetic field on boundary layer flow of incompressible electrically conducting water based nanofluids and a variation of heated vertical slip boundary condition. They considered three different water based nanofluids such as copper (cu), aluminium oxide $\left(\mathrm{Al}_{2} \mathrm{O}_{3}\right)$ and titanium dioxide $\left(\mathrm{TiO}_{2}\right)$ and characteristics of these fluids are shown graphically and analysed along with the parameters like solid volume fraction $\phi$, magnetic field parameter, buoyancy effect, Eckert number, suction/injection parameter, biot number and slip parameter on non-dimensional velocity, temperature, skin friction coefficient and heat transfer rate respectively. Also, the author (Yacob et al., 2013) investigated the nature of the fluid flow and heat transfer in the presence of the nanofluid with numerical methods and they used the three kinds of nanoparticles, they are copper (cu), aluminium 
$\left(\mathrm{Al}_{2} \mathrm{O}_{3}\right)$ and titanium $\mathrm{TiO}_{2}\left(\mathrm{TiO}_{2}\right)$ with the water base fluid respectively. The authors (Makinde et al., 2013) investigated the combined effects of buoyancy force, convective heating, Brownian motion, thermophoresis and magnetic field on stagnation point flow and heat transfer due to number Le, the Brownian motion parameter $\mathrm{Nb}$, thermophoresis parameter $\mathrm{Nt}$ and convection biot number $\mathrm{Bi}$ and by employing the numerical methods they solve the governing equations to found the Makinde and Aziz (2011) concentrated on boundary layer flow this is propagated in a nanofluid due to linearly stretching sheet. They used numerical method and obtained equations shown that are effects on Brownian motion and thermophoresis. The different thermal conditions of constant temperature or constant heat flux are employed for convective heating boundary condition. In the solution part they nanofluid flow towards a stretching sheet and numerical results are used to find the solutions of governing equations in their analysis. They noticed that the dual solution exist for shrinking case and both skin friction co-efficient and local Sherwood number decreases while as increasing with the local nusselt number with increasing intensity of buoyancy force.

Shariat et al. (2014) analysed a impact of nanoparticle mean diameter, laminar mixed convection $\left(\mathrm{Al}_{2} \mathrm{O}_{3}\right)$ of buoyancy force of nanofluid flow in an elliptic duct employing two phase mixture model and three dimensional Navier-stokes energy and volume fraction equations are explained using finite volume method (FVM). A continuous heat flux applied to the wall boundary conditions. They considered the brownian motions of nanoparticles to determined the thermal conductivity and dynamics viscosity of $\left(\mathrm{Al}_{2} \mathrm{O}_{3}\right)$ - water nanofluid depends on temperature. Here the authors employed various basic parameter, their results are presented through graphs and discussed well. When we think about their output, it is says that as secondary flows has a major role on thermal and hydraulic behaviors of nanofluid flow and distribution which affected by the both nanoparticle diameter and buoyancy force. Finally their conclusion said that, there are non-linear relations between the size of the nanoparticle and the nanofluid flow behaviors. The authors (Das et al.,2014) well investigated on MHD boundary layer slip flow and heat transfer of nanofluid of vertical stretching sheet with non uniform heat generation/absorption.

(Hayat et al., 2015) addressed in their studies the mixed convection flow of non-newtonian nanofluid in the presence of thermal radiation, heat source/sink and first order chemical reaction. The authors adopted the casson fluid model. They used convective boundary conditions for heat and mass transfer and classical transformation are used as well as a series of solutions of the problem are obtained. The author Pal and Mandal (2015) study deals with the MHD boundary layer flow of an electrically conducting convective nanofluid are used in a non-linear vertical shrinking sheet with viscous ohmic dissipation. They pointed various parameter in their studies and basic non-metallic nanoparticles like copper $(\mathrm{cu})$, alumina $\left(\mathrm{Al}_{2} \mathrm{O}_{3}\right)$ and titanium $\left(\mathrm{TiO}_{2}\right)$ in the base fluid water. Hence their result reveals that as increasing the value of Hartmann number leads to decrease in the velocity profiles while opposite effects found in the temperature profile along with that they focused that as increasing the nanoparticle which results as improvement of heat transfer at the boundary layer. Specially, they got the result as dual solution in the velocity and temperature fields for bigger values of suction/injection shrinking sheet problem.

Ships at sea, down to the depths, filming titanic, into the skies, airships etc are the real life applications and these all works by the principle of buoyancy. Hence, the author Hsiao (2016) investigated about the stagnation nano-energy conversion problems for conjugate mixed convection heat and mass transfer with electrical magneto hydrodynamic (EMHD) and heat source /sink effects nanofluid flow field over a slip boundary stretching sheet surface. The authors Hayat et al., (2016) well considered a boundary layer flow of a nonnewtonian fluid produced by a vertical stretching sheet. [Akbar et al., (2014) Makinde and Olanrewaju (2010)] well studied the effects of thermal buoyancy on thermal boundary layer over a vertical plate with uniform stream fluid numerically with shooting technique together with fourth order Runge-kutta technique. The authors investigated the effects of prandlt number (Pr), local grashof number $\mathrm{Gr}_{\mathrm{x}}$ and the convective heat transfer $\mathrm{Bi}_{\mathrm{x}}$ plotted through figures and discussed well, their results are well agreement comparing with previously published and present results respectively. The similar work may be seen by [Pantokratoras (2015); Cortell (2005); Aziz (2009); Makinde (2009); Nandeppanavar and Shakunthala (2016); Nandeppanavar and Shakunthala (2016); (Ibrahim et al 2013); (Khan et al., 2014); (Angayarkanni et al., 2015); (Devendiran et al., 2016)]. After studying the all above studies, we were found that nobody has taken analysis on buoyancy effects of flow and heat transfer of blasius flow of nanofluid in presence of carbon nanotubes. Hence, in the present study we have chosen analysis on buoyancy effects on flow and heat transfer of nanofluids with carbon nanotubes due a vertical plate is considered for investigation.

\section{MATHEMATICAL FORMULATION}

We consider steady two dimensional boundary layer flow of a nanofluid over a vertical stretching sheet. The flow takes place $y \geq 0$,

where $y$ is the co-ordinate measured normal to the stretching sheet. The classical equations for continuity, momentum and energy of nanofluids are obtained in Cartesian co-ordinates $\mathrm{x}$ and $\mathrm{y}$ as follows,

$$
\begin{aligned}
& u_{x}+v_{y}=0 \\
& u u_{x}+v u_{y}=v_{n f} u_{y y}+g \beta\left(T-T_{\infty}\right) \\
& u T_{x}+v T_{y}=\alpha_{n f} T_{y y}
\end{aligned}
$$

where $u$ and $v$ are the $\mathrm{x}$ (along the plate) and $\mathrm{y}$ (normal to the plate) components of the velocities, $\mathrm{T}$ is the temperature, $v_{n f}$ is the kinematic viscosity of the fluid and $\alpha_{n f}$ is the thermal diffusivity of the fluid, $\mathrm{g}$ is the gravitational force and $\beta$ is the thermal expansion coefficient.

$$
\left.\begin{array}{l}
\mu_{n f}=\frac{\mu_{f}}{(1-\phi)^{25}}, \rho_{n f}=(1-\phi) \rho_{f}+\phi \rho_{s}\left(c_{p}\right)_{\text {CNT }} \\
\alpha_{\text {nff }}=\frac{k_{n f}}{\rho_{\text {nff }}\left(C_{p}\right)_{n f}}, \frac{k_{n f}}{k_{f}}=\frac{(1-\phi)+2 \phi \frac{k_{C N T}}{k_{C N T}-k_{f}} \ln \frac{k_{C N T}+k_{f}}{2 k_{f}}}{(1-\phi)+2 \phi \frac{k_{f}}{k_{\mathrm{CNT}}-k_{f}} \ln \frac{k_{C N T}+k_{f}}{2 k_{f}}} \\
\left(\rho c_{p}\right)_{\text {nf }}=(1-\phi)\left(\rho c_{p}\right)_{f}+\phi\left(\rho c_{p}\right)_{\mathrm{CNT}}
\end{array}\right\}
$$

Here, $\mu_{\mathrm{f}}$ is the viscosity of the base fluid, $\phi$ is the nanoparticle volume fraction, $\mathrm{K}_{\mathrm{nf}}$ is the thermal conductivity of nanofluid, $\mathrm{K}_{\mathrm{f}}$ and $\mathrm{K}_{\mathrm{CNT}}$ are the thermal conductivities of the base fluid and carbon nanotubes respectively, $\rho_{n f}$ and $\rho_{\text {cor }}$ are the thermal conductivity of the base fluid and carbon nanotubes, respectively (we can refer by Akbar et al., 2014).

The boundary conditions of the flow can be written as,

$\left.\begin{array}{l}u=0, v=0, T=T_{w} \text { at } y=0 \\ u=U_{\infty}, T \rightarrow T_{\infty} \quad \text { as } y \rightarrow \infty\end{array}\right\}$

Imposing the similarity transformations as,

$\eta=\sqrt{\frac{U_{\infty}}{v x}} y, u=U_{\infty} f_{\eta}(\eta), v=\frac{1}{2} \sqrt{\frac{v U_{\infty}}{x}}\left[\eta f_{\eta}-f\right]$, $\theta(\eta)=\frac{T-T_{\infty}}{T_{f}-T_{\infty}}$

Here $\eta$ is the similarity variable, $T_{f}$ is the fluid temperature and $T_{\infty}$ is the ambient temperature.

On substituting the Eq. (6) in (1) satisfies it in common and Eq.(2) and (3) turn down as, 


$$
\begin{gathered}
f_{\eta \eta \eta}+(1-\phi)^{2.5}\left[(1-\phi)+\phi \frac{(\rho C p)_{C N T}}{\rho_{f}}\right]\left(\frac{f f_{\eta \eta}}{2}+G r \theta\right)=0 \\
\left(\frac{k_{n f}}{k_{f}}\right) \theta_{\eta \eta}+\operatorname{Pr}\left[(1-\phi)+\phi \frac{(\rho C p)_{C N T}}{(\rho C p)_{f}}\right] \frac{f \theta_{\eta}}{2}=0
\end{gathered}
$$

Where $\operatorname{Pr}=\left(\frac{\mu c_{p}}{k}\right)_{f}$ is the Prandtl number and primes is represents the differentiation w.r.t $\eta$.

The converted boundary conditions take the form,

$$
\left.\begin{array}{l}
f(\eta)=0, f_{\eta}(\eta)=0 \text { at } \eta=0 \\
f(\eta) \rightarrow 1, \theta(\infty) \rightarrow 0 \text { as } \eta \rightarrow \infty
\end{array}\right\}
$$

To get the solution of the momentum and energy equations of the parameter $G r_{x}$ necessarily be a constant and which should not be a function of $\mathrm{x}$.

$\left.G r_{x}=\frac{\gamma \times g \beta\left(T-T_{\infty}\right)}{U_{\infty}^{2}}\right\}$

This condition is used when the thermal expansion coefficient $\beta$ is proportional to $x^{-1}$. Therefore we assume

$\left.\beta=m x^{-1}\right\}$

By substituting Eq. (11) in (10) we get the $G r$ as

$$
\left.G r=\frac{\operatorname{vgm}\left(T-T_{\infty}\right)}{U_{\infty}^{2}}\right\}
$$

Here Gr defined by the Eq. (12) and called as Grashof number, the solutions of the equations (7), (8) w.r.t (9) provide the numerical solutions w.r.t boundary conditions.

The physical quantities for the local skin friction co-efficient $C_{f}$ and the local nusselt number $\mathrm{Nu}_{x}$ are taken as,

$\left.\begin{array}{l}C_{f}=\frac{\tau_{w}}{\rho_{f} U_{w}^{2}}, N u_{x}=\frac{q_{w}}{k_{f}\left(T_{f}-T_{\infty}\right)} \\ \text { where } \tau_{w}=\mu_{n f}\left(\frac{\partial u}{\partial y}\right)_{y=0}, q_{w}=-x k_{n f}\left(\frac{\partial T}{\partial y}\right)_{y=0}\end{array}\right\}$

Using the Eq. (5) and Eq. (6) in (13) we obtained as,

$\left.\operatorname{Re}_{x}^{\frac{1}{2}} c_{f}=\frac{f^{\prime \prime}(0)}{(1-\phi)^{2.5}}, \quad \operatorname{Re}_{x}^{\frac{-1}{2}} N u_{x}=\frac{-k_{n f}}{k_{f}} \theta^{\prime}(0)\right\}$

Where $\operatorname{Re}_{x}^{\frac{1}{2}}=\left(\frac{U_{\infty} x}{v_{f}}\right)^{\frac{1}{2}}$ represents the Reynolds number, $\mathrm{C}_{\mathrm{f}}$ Local Skin friction and $\mathrm{Nu}_{\mathrm{x}}$ local nusselt number.

\section{METHOD OF NUMERICAL SOLUTION}

The ODE's (7) and (8) are converted into following system of Eqn./s as

$$
\left.\begin{array}{l}
f_{\eta}=p \\
f_{\eta \eta}=p^{\prime} \\
f_{\eta \eta \eta}=-(1-\phi)^{2.5}\left\{\left(1-\phi+\phi \frac{\rho_{C N T}}{\rho_{f}}\right)\left(\frac{f q}{2}+G r \theta\right)\right\}
\end{array}\right\}
$$

$$
\left.\theta^{\prime \prime}=z^{\prime}=-\operatorname{Pr}\left[\frac{1-\phi+\phi\left(\frac{\left(\rho C_{p}\right)_{c N T}}{\left(\rho C_{p}\right)_{f}}\right)}{\frac{k_{n f}}{k_{f}}}\right]\left\{\frac{f z}{2}\right\}\right\}
$$

With corresponding boundary conditions

$$
\left.\begin{array}{l}
f(0)=0, p(0)=0, q(0)=s_{1} \\
z(0)=1, z(0)=s_{2}
\end{array}\right\}
$$

To integrate Eq. (15) and (16) with initial conditions (17), $q(0)$ and $z(0)$ are required, but no such values are given in the boundary conditions. Hence suitable guesses for $q(0)$ and $z(0)$ taken S1 and S2 respectively are chosen (values for $\mathrm{S}_{1}$ and $\mathrm{S}_{2}$ are chosen) at $\eta_{\max }=14, f_{\eta}(10)=0 \& \theta(10)=0$. The guessed values for $q(0)$ and $z(0)$ are adjusted to give a better approximation for the solution. We take series values of $q(0)$ and $z(0)$ apply classical RK method with step size $h=0.01$. The said procedure is repeated until we get the converging asymptotic results within a tolerance of $10^{-6}$.

\section{RESULT AND DISCUSSION}

The solutions of the coupled nonlinear ordinary differential equations are carried out and plotted various graphs for thermophysical parameters which are very helpful controlling in flow region. The thermal buoyancy parameter Gr is very helpful in cooling the system (if $G r>0$ corresponding to the cooling systems). In engineering cooling applications the cooling problems are used frequently for example electronic machines, individual cooling heat sinks and electrical devices.

Fig.1 shows the schematic diagram of the considered problem. Fig .2 (a) \& (b) and Fig.3 (a) \& (b) are the flow profile for different values of buoyancy parameter $\mathrm{Gr}$ in absence of $\phi$ and in presence of $\phi$ respectively for SWCNT and MWCNT cases. On observing these plots the flow profile increases as increase in the parametric values of $\mathrm{Gr}$ in both cases SWCNT and MWCNT both in absence and presence of $\phi$.

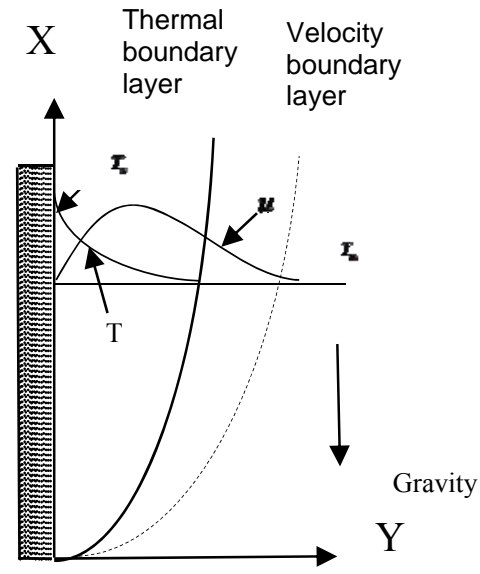

Fig. 1 Physical Configuration 

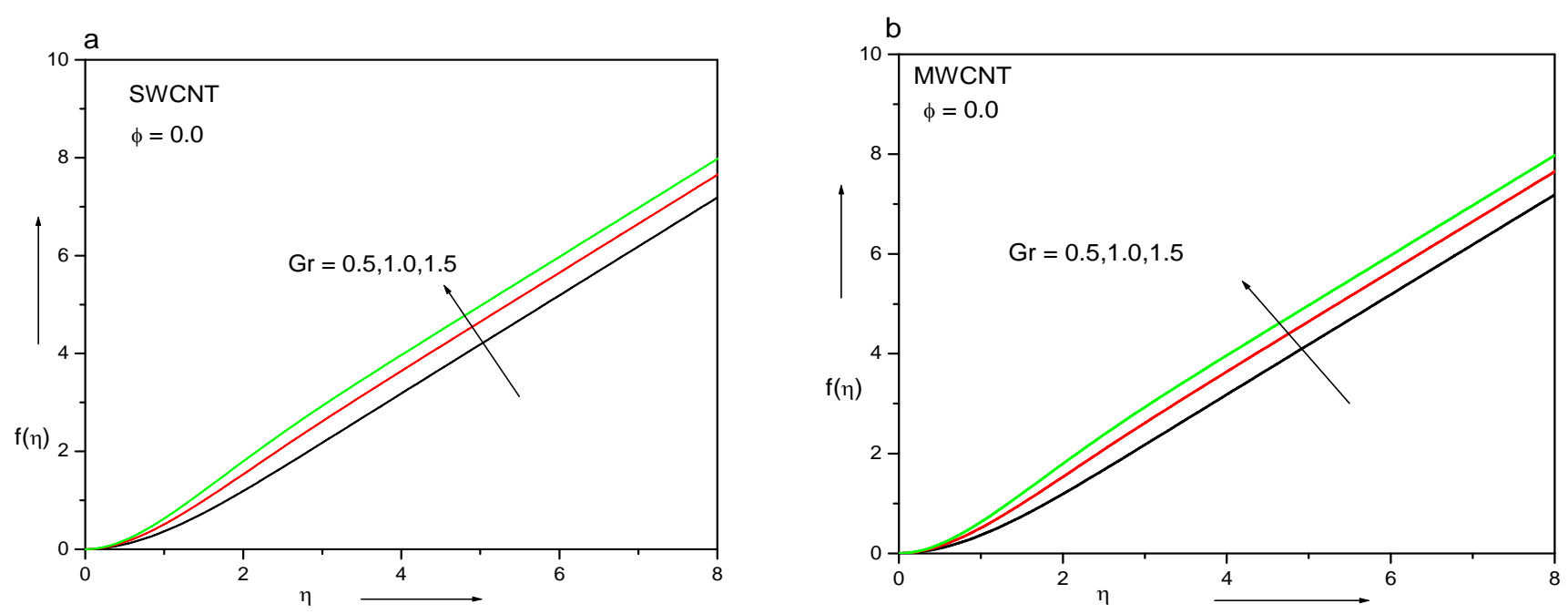

Fig. 2 Flow profile for Gr when $\operatorname{Pr}=1$
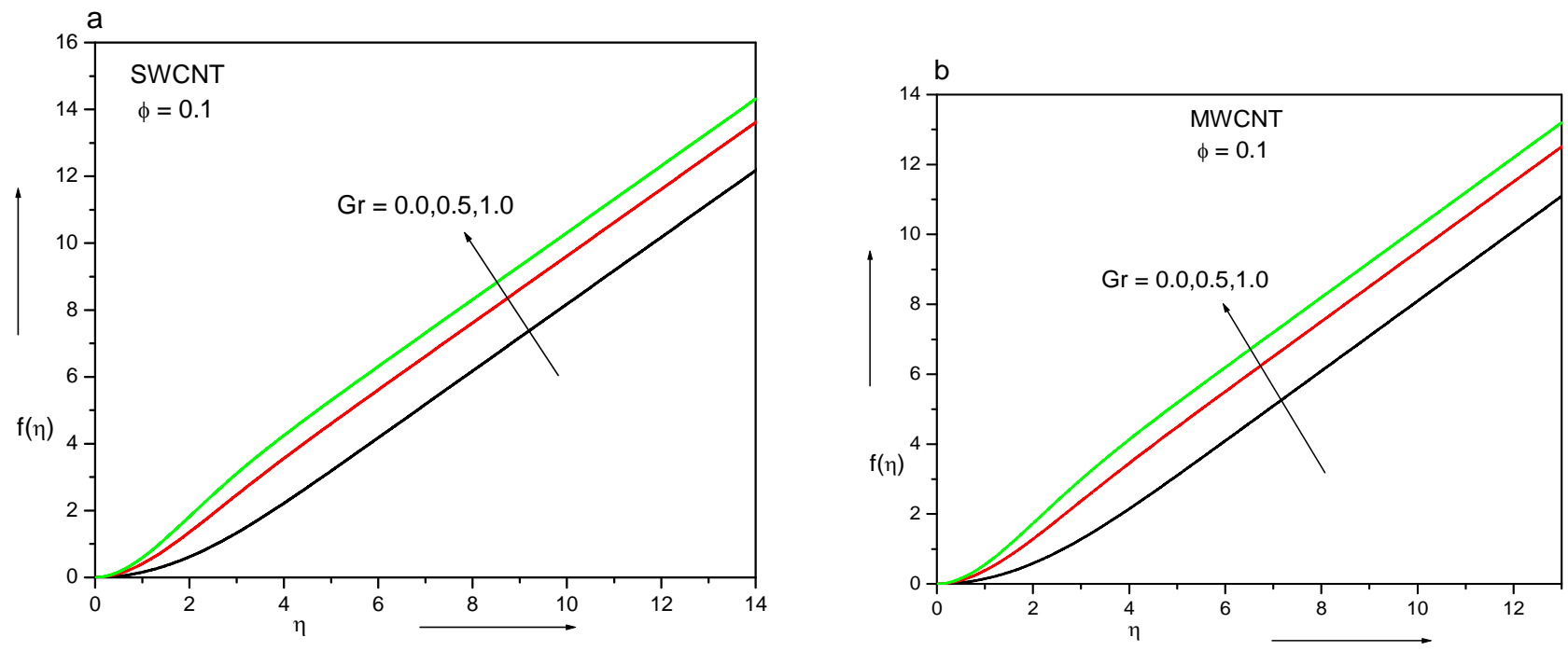

Fig. 3 Flow profile for $G r$ when $\operatorname{Pr}=1$
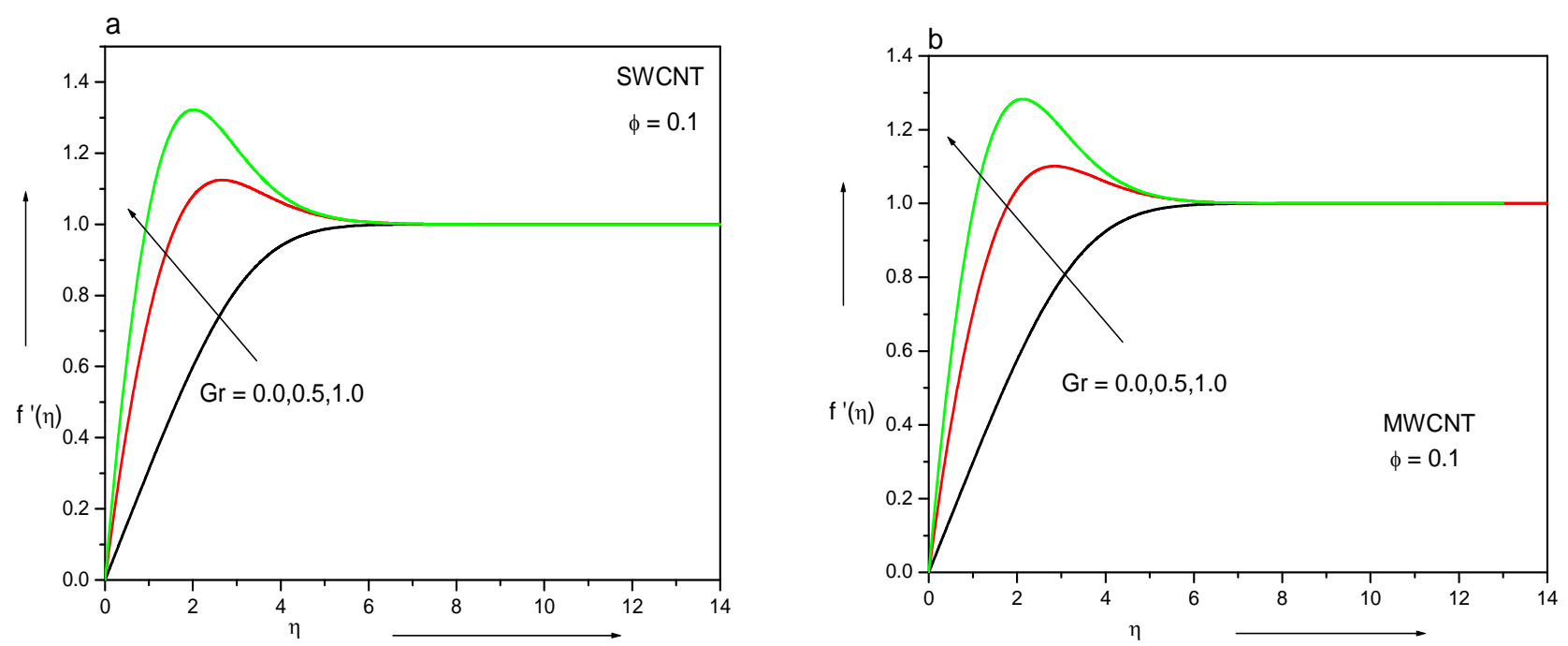

Fig. 4 Velocity profile for $G r$ when $\operatorname{Pr}=1$ 
Fig. 4(a) \& (b) are plotted to show the velocity profile for various values of $\mathrm{Gr}$. Here we can see that the fluid velocity is zero at the vertical plate surface and enhance gradually away from the plate towards the force stream value satisfying the boundary conditions. Here $G r>0$ shows the heating of the fluid cooling the surface increase in $G r$ means increase in temperature difference ${\left(T_{f}-T_{\infty}\right)}_{\text {which heads }}$ to an enhancement of $f^{\prime}(\eta)$ thus an increase in momentum boundary layer thickness, this effects is done in both SWCNT and MWCNT cases.

Fig.5 (a) \& (b) and Fig.6 (a) \& (b) are plotted for $f^{\prime \prime}(\eta)$ profile for different values of $G r$ as increase in parametric values of $G r$ increases the $f^{\prime \prime}(\eta)$ profile increases in absence of nanoparticle volume fraction $\phi$ and in presence of nanoparticle volume fraction $\phi$ and the profile behavior is similar in both SWCNT and MWCNT.

Fig. 7 (a) \& (b) are plotted for velocity profile for different values of $\phi$ and $G r$. We can see that the result for variation of $G r$ is similar as explained in fig 4 (a) \& (b) but for the variation of $\phi$ the velocity increases as increase in presence of and in absence of $\mathrm{Gr}$. Magnitude of velocity profiles are more in presence of $\mathrm{Gr}$ as compared to the same profiles in absence of $G r$.
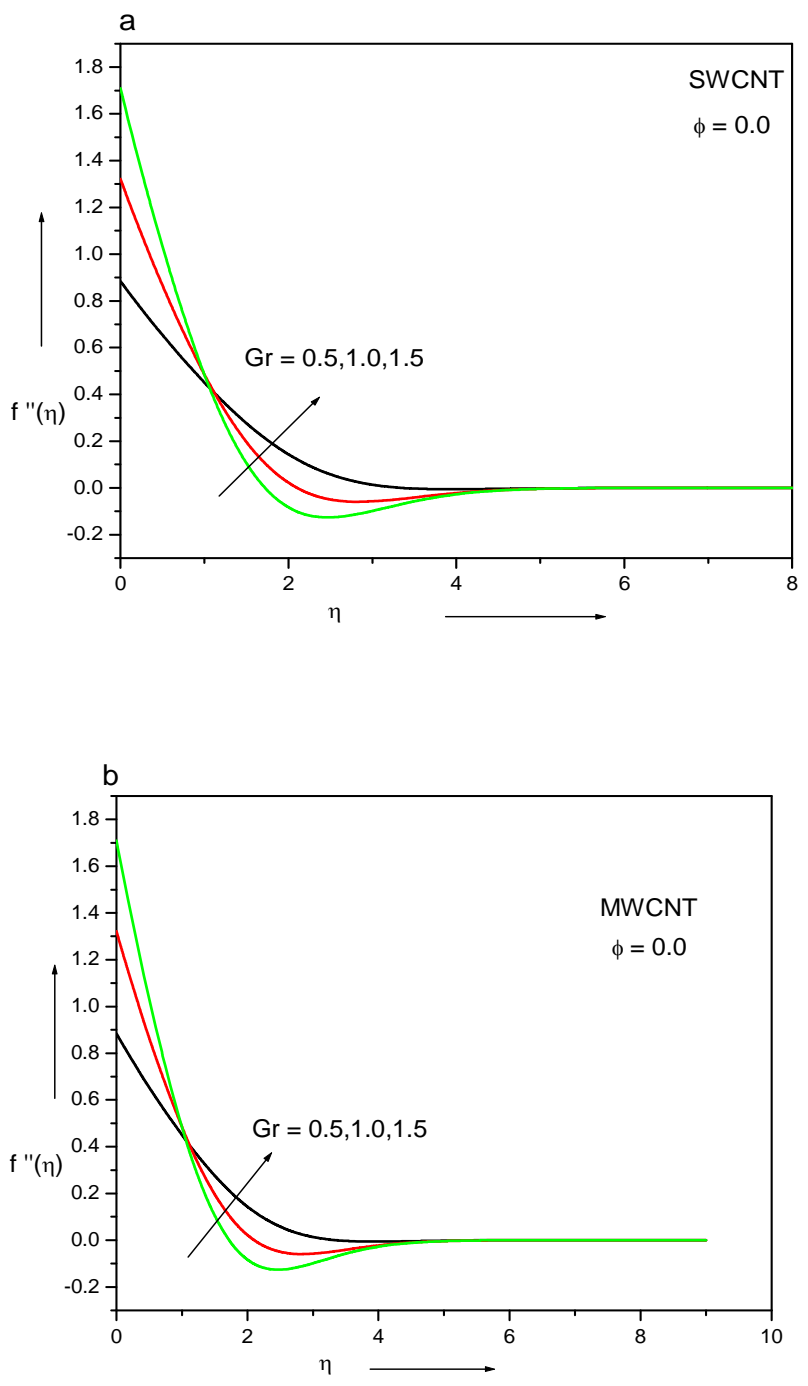

Fig. 5 Skin friction profile for $G r$ when $\operatorname{Pr}=1$
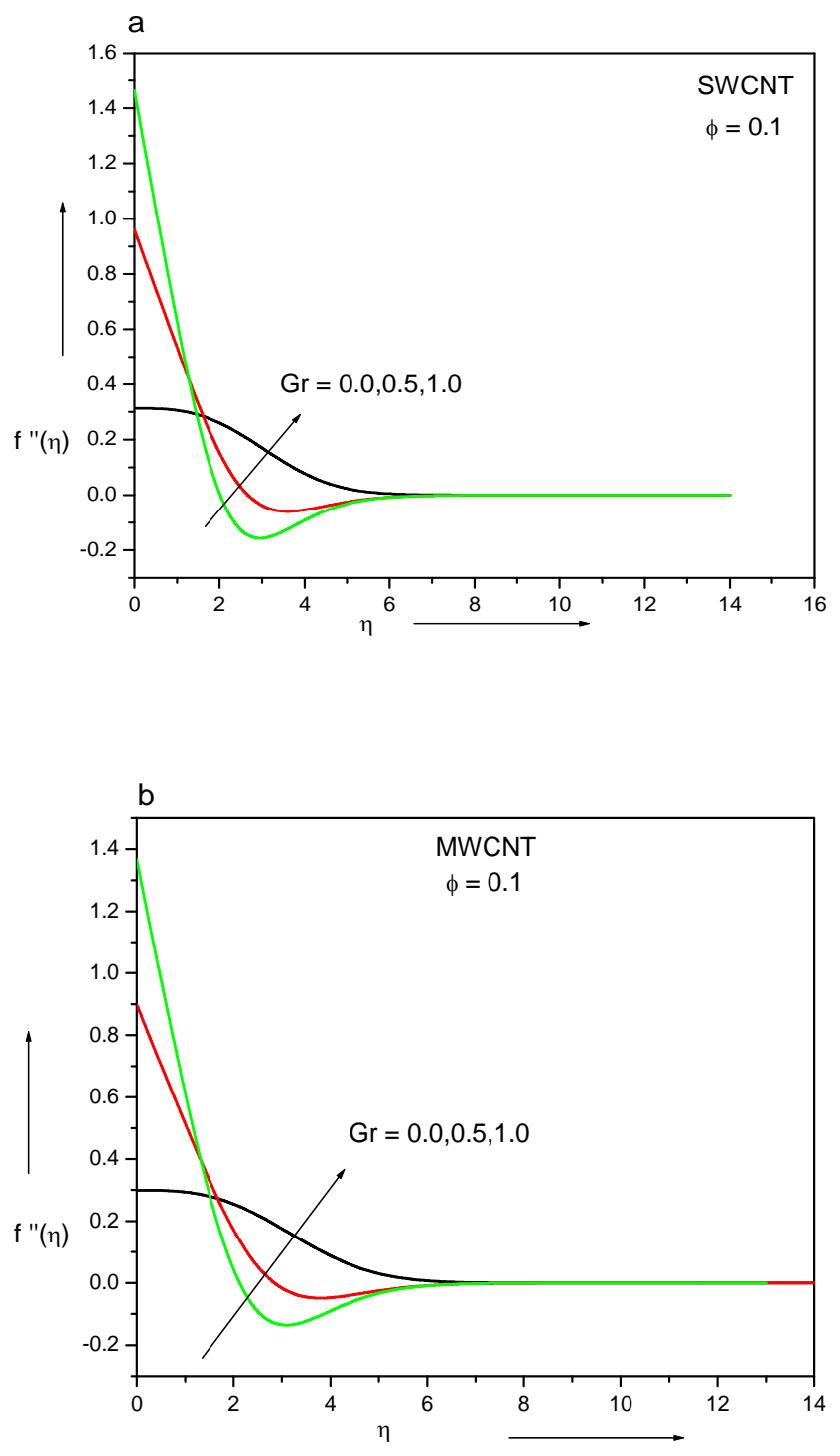

Fig. 6 Skin friction profile for $G r$ when $\operatorname{Pr}=1$

Fig. 8 (a) \& (b) and Fig. 9(a) \& (b) temperature profile plotted for different values of $G r$ in the absence and presence of $\phi$ respectively. The quite opposite behavior observed as compared to the effect of $\mathrm{Gr}$ on velocity profile. Here we can observed that increase in $G r$ the temperature field is suppressed and consequently the thermal boundary layer thickness become thin, hence due to buoyancy force the magnitude of the rate of heat transfer from the surface increases. The effect is similar in both SWCNT and MWCNT cases and in absence and in presence of solid volume friction $\phi$.

See Fig.10 (a) \& (b) are also plotted for temperature profiles for various values of $\phi$ in presence and in absence of Grashof number $G r$. It is noticed that temperature is decreasing as values of nanoparticle volume fraction $\phi$ increasing it is true in absence and in presence of Grashof number $\mathrm{Gr}$ due to increase in the thermal conductivity of CNT's with the solid volume fraction. The thermal boundary layer thickness decreases. It is similar in both SWCNT and MWCNT. The magnitude of temperature is lesser in presence of $\mathrm{Gr}$ as compared to in absence of $G r$. 

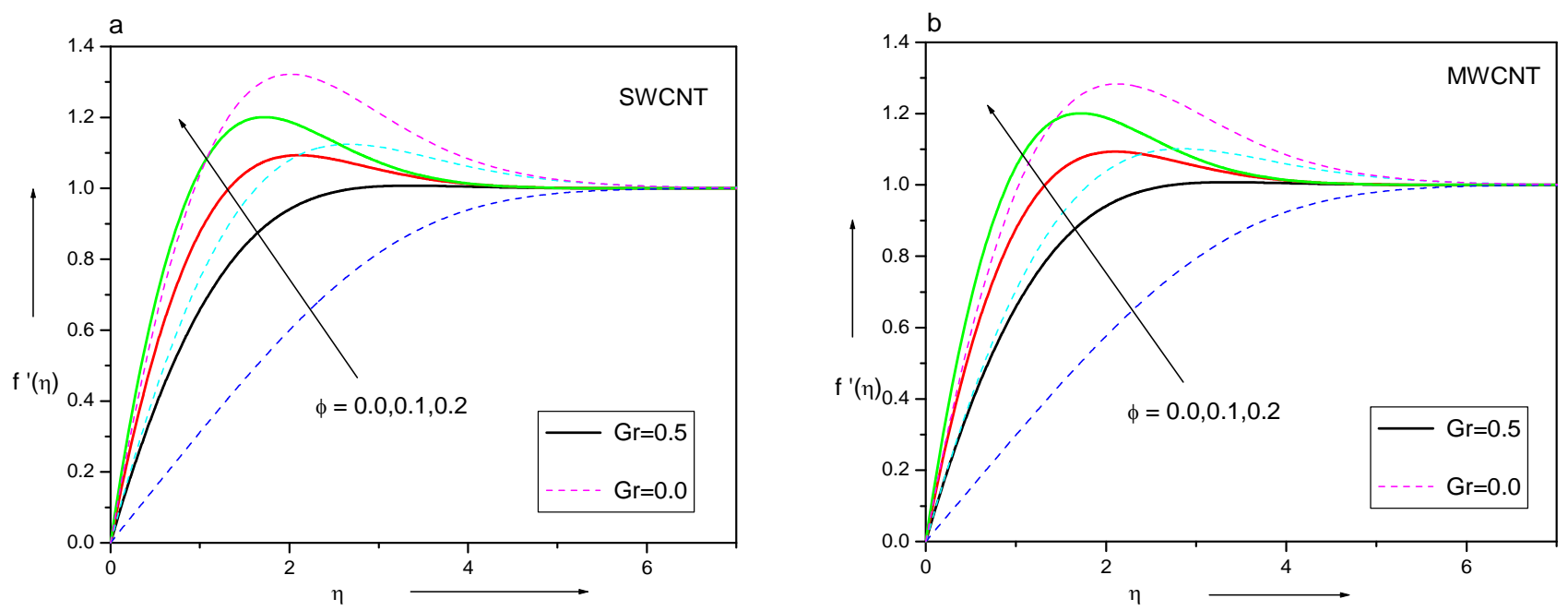

Fig. 7 Mixed velocity profile for $G r$ when $\operatorname{Pr}=1$
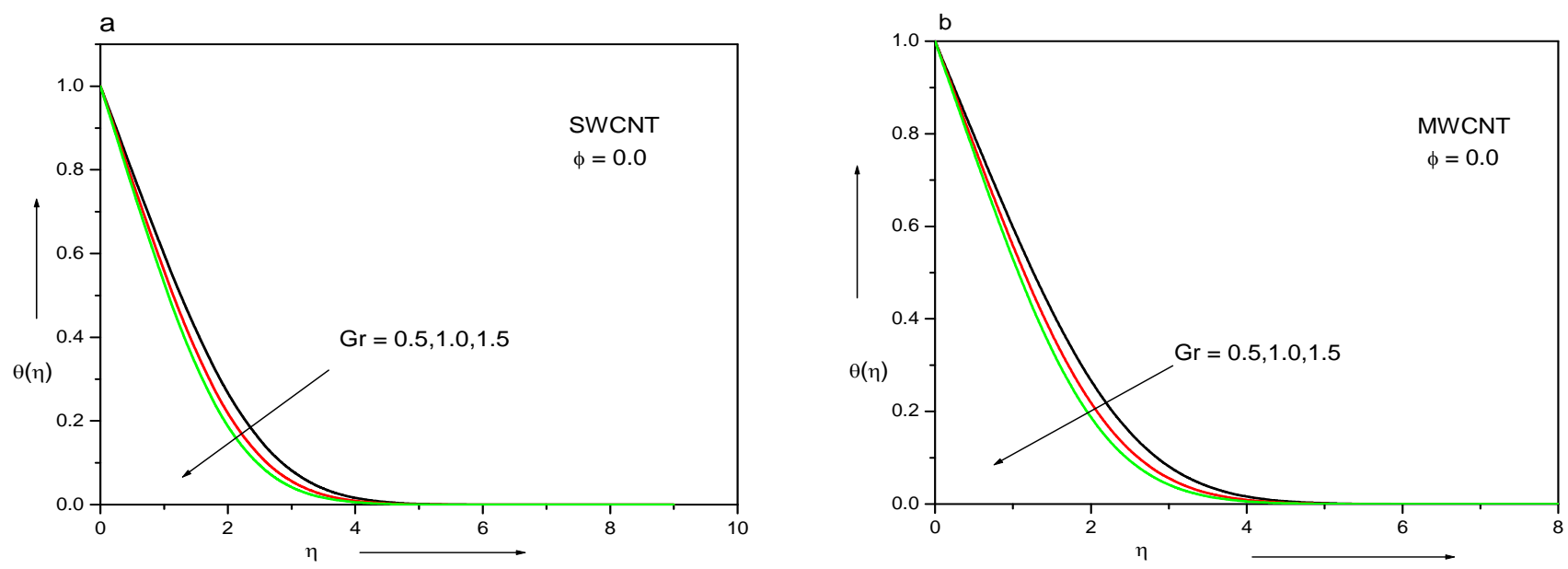

Fig. 8 Temperature profile for $G r$ when $\operatorname{Pr}=1$
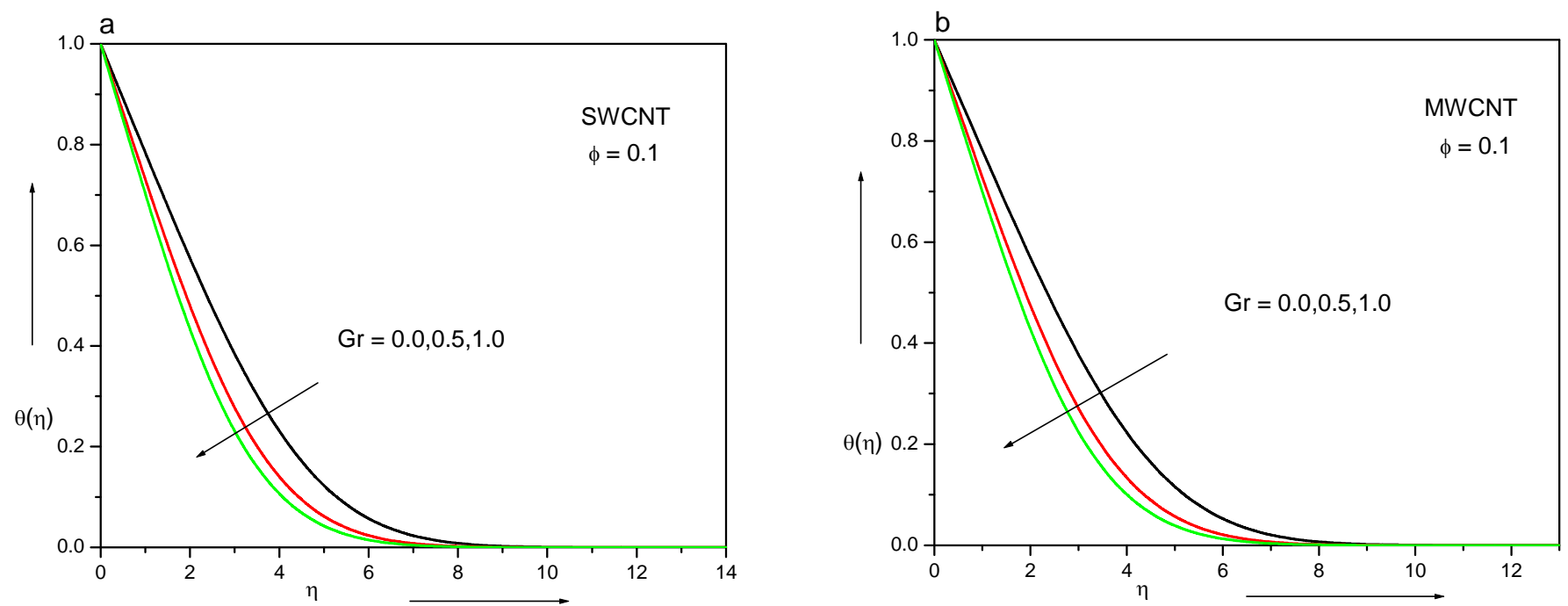

Fig. 9 Temperature profile for $G r$ when $\operatorname{Pr}=1$ 

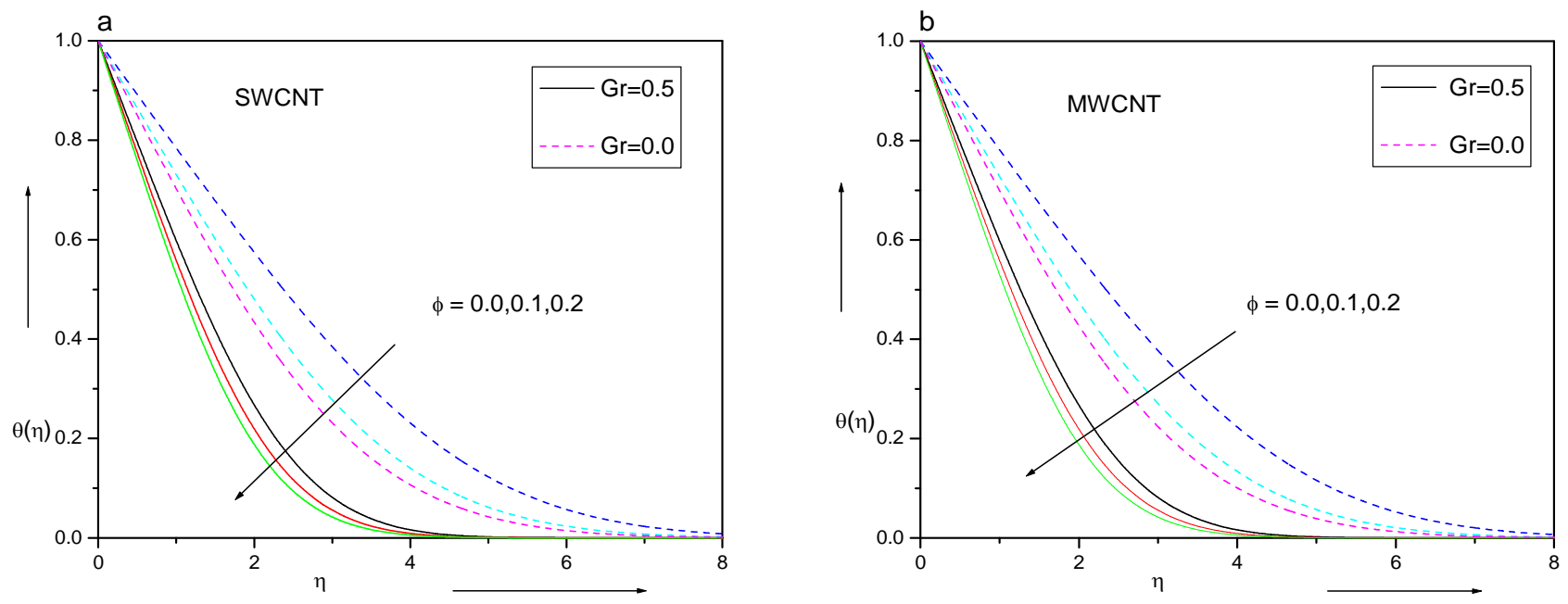

Fig. 10 Mixed temperature profile for volume fraction when $\operatorname{Pr}=1$
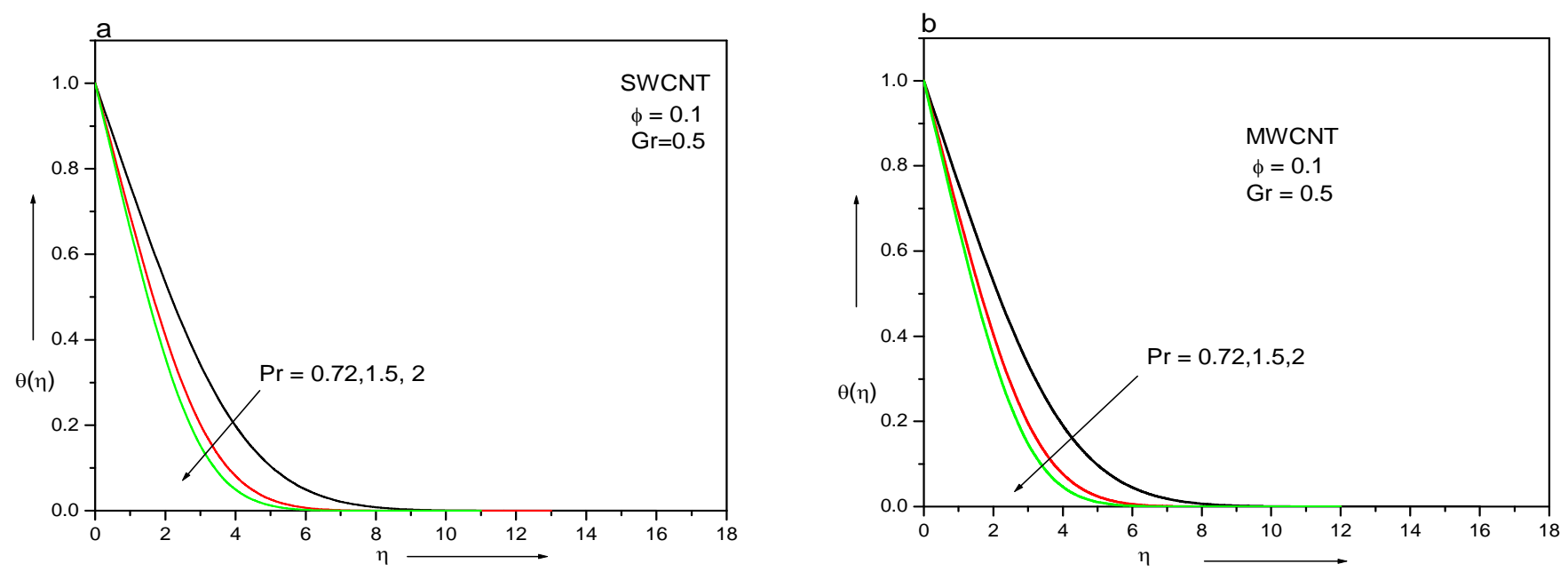

Fig. 11 Temperature profile for Pr
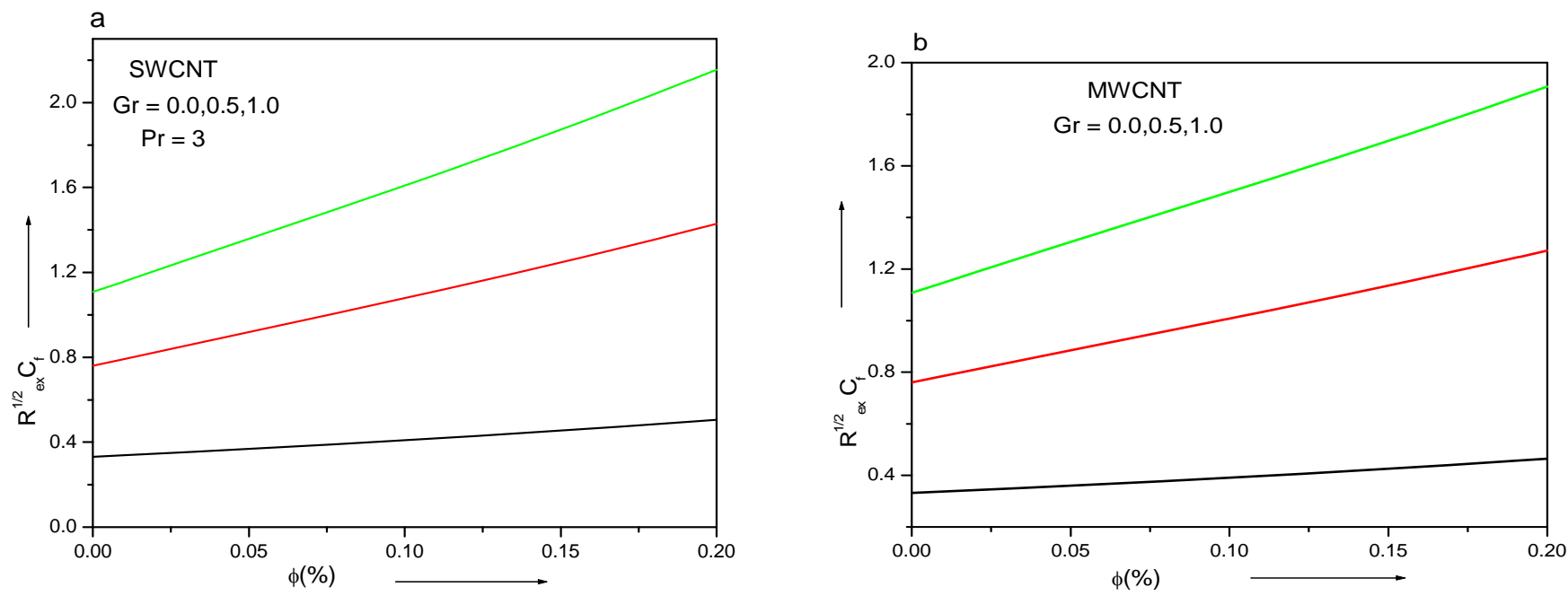

Fig. 12 Local Skin-Friction profile 
Fig.11 (a) \& (b) represent the effect of Prandlt number on temperature profile for SWCNT and MWCNT respectively. We know that increasing values of Pr leads to decrease the thermal conductivity that is the increasing values of Pr reduces the thermal boundary layer thickness hence cooling of the heated plate can gradually be improved by choosing a proper coolant with large $\mathrm{Pr}$ which similar in presence of both SWCNT and MWCNT.

Fig.12 (a) \& (b) show the skin friction profile for different values of solid volume fraction in presence and absence of SWCNT and MWCNT for different values of $G r$. It is noticed that skin friction coefficient increase with increase in $\mathrm{Gr}$ values.
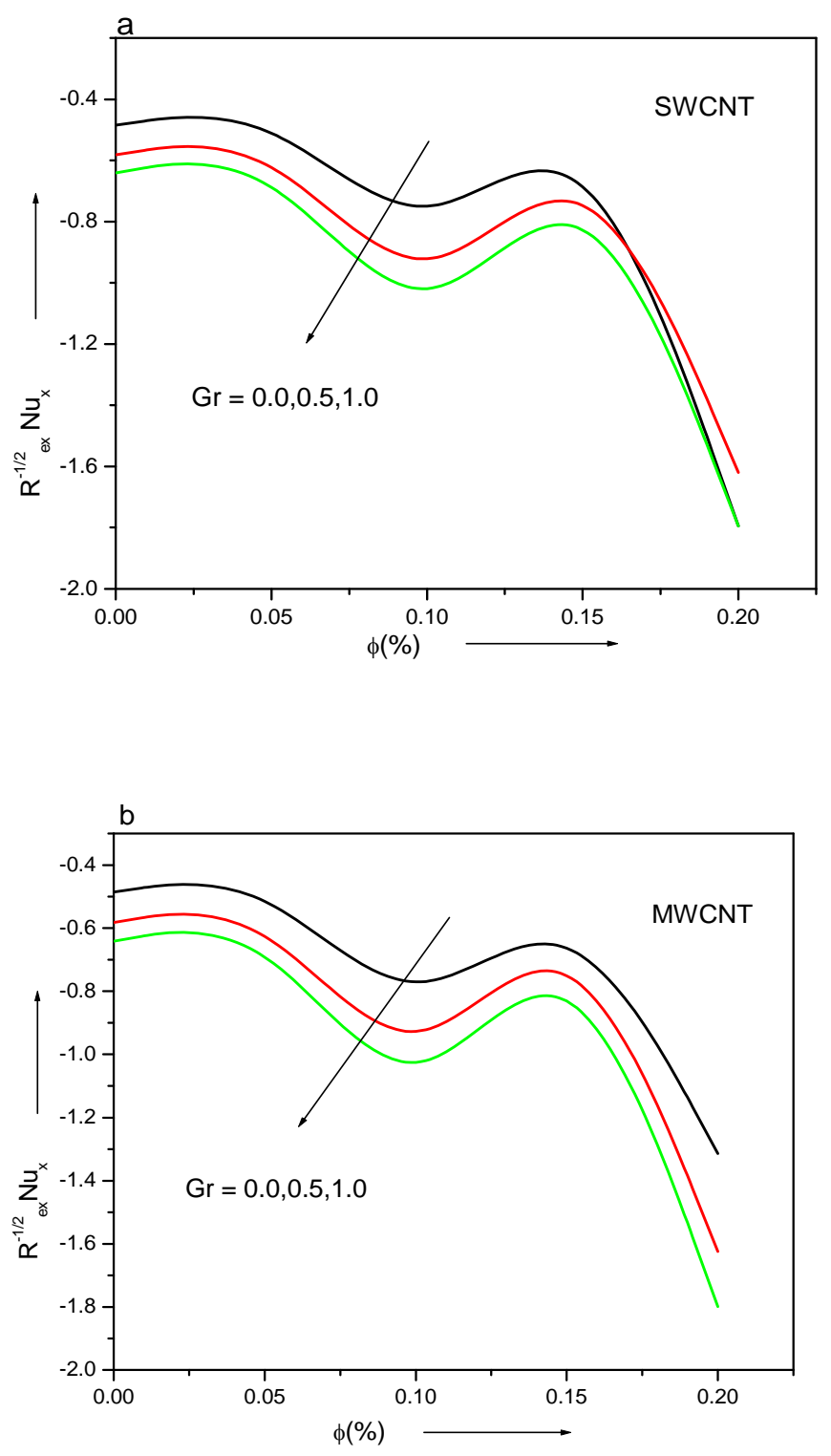

Fig. 13 Local Nusselt number profile

Fig.13 (a) \& (b) are plotted for different values of $G r$ w.r.t $\phi$, the profiles are decreasing as increasing values of $G r$ and $\phi$ respectively.

In table 1 we have calculated the local skin friction value for different values of $\phi$. To validate our results we have compared our

results with earlier results of (Khan et al., 2014), which show a very good agreement in absence of $\mathrm{Gr}$.

The table 1 and 2 shown for the comparision values of a local skinfriction and local nusslet number when $G r=0.0$ and $\operatorname{Pr}=3.0$ in both the cases single wall corbon nanotube (SWCNT) and muti wall corbon nanotube(MWCNT).

Table 1 Computation showing different values of $f^{\prime \prime}(0), \theta^{\prime}(0), C_{f}$ and $N u_{x}$ for different values of physical parameters

\begin{tabular}{ccccc}
\hline \hline \multicolumn{5}{c}{ SWCNT $\mathrm{Gr}=0.0 \& \mathrm{Pr}=3$} \\
\hline \hline \multicolumn{6}{c}{$f^{\prime \prime}(\eta)$} & $-\theta^{\prime}(\eta)$ & $C_{f}$ & $-N u_{x}$ \\
\hline & & & & \\
& & & & \\
0.0 & 0.332057 & 0.485048 & 0.332057 & 0.485048 \\
0.05 & 0.323117 & 0.380988 & 0.367325 & 0.411616 \\
0.1 & 0.313611 & 0.321276 & 0.408118 & 0.934531 \\
0.15 & 0.301927 & 0.279179 & 0.453268 & 0.346509 \\
0.2 & 0.289174 & 0.856680 & 0.505167 & 0.79421 \\
& & & & \\
\hline \hline
\end{tabular}

Table 2 Computation showing different values of $f^{\prime \prime}(0), \theta^{\prime}(0), C_{f}$ and $N u_{x}$ for different values of physical parameters.

\begin{tabular}{ccccc}
\hline \hline \multicolumn{5}{c}{ SWCNT $\mathrm{Gr}=0.5 \& \mathrm{Pr}=3$} \\
\hline \hline \multicolumn{6}{c}{$f^{\prime \prime}(\eta)$} & $-\theta^{\prime}(\eta)$ & $C_{f}$ & $-N u_{x}$ \\
\hline & & & & \\
0.0 & 0.760295 & 0.581940 & 0.760295 & 0.58194 \\
0.05 & 0.808298 & 0.464386 & 0.918888 & 0.501718 \\
0.1 & 0.827307 & 0.395061 & 1.07662 & 1.14916 \\
0.15 & 0.828929 & 0.345242 & 1.24443 & 0.428504 \\
0.2 & 0.817788 & 0.305893 & 1.42862 & 1.61936
\end{tabular}

Table 3 Computation showing different values of $f^{\prime \prime}(0), \theta^{\prime}(0), C_{f}$ and $N u_{x}$ for different values of physical parameters.

\begin{tabular}{ccccc}
\hline \hline \multicolumn{5}{c}{ MWCNT $\mathrm{Gr}=1.0 \& \mathrm{Pr}=3$} \\
\hline \hline \multicolumn{6}{c}{$f^{\prime \prime}(\eta)$} & $-\theta^{\prime}(\eta)$ & $C_{f}$ & $-N u_{x}$ \\
\hline & & & & \\
0.0 & 1.107161 & 0.640803 & 1.10716 & 0.640803 \\
0.05 & 1.149820 & 0.516247 & 1.307714 & 0.557748 \\
0.1 & 1.150866 & 0.439711 & 1.49768 & 1.27904 \\
0.15 & 1.129019 & 0.383971 & 1.69494 & 0.476573 \\
0.2 & 1.091964 & 0.339780 & 1.90758 & 1.79875 \\
& & & & \\
\hline \hline
\end{tabular}


Similarly, the comparision results in Table 3,4,5 and 6 given the comparision values for different values of different physical parameters and different values of Grashof (Gr) number and prandlt number $(\mathrm{Pr})$ which are given satifaction of the boundary conditions respectively.

Table 4 Computation showing different values of $f^{\prime \prime}(0), \theta^{\prime}(0), C_{f}$ and $N u_{x}$ for different values of physical parameters.

\begin{tabular}{ccccc}
\hline \hline \multicolumn{5}{c}{ MWCNT $\mathrm{Gr}=0.0 \& \mathrm{Pr}=3$} \\
\hline \hline$\phi$ & $f^{\prime \prime}(\eta)$ & $-\theta^{\prime}(\eta)$ & $C_{f}$ & $-N u_{x}$ \\
\hline & & & & \\
0.0 & 0.332057 & 0.485048 & 0.323057 & 0.485048 \\
0.05 & 0.316109 & 0.384329 & 0.359359 & 0.415225 \\
0.1 & 0.299756 & 0.324376 & 0.390087 & 0.943548 \\
0.15 & 0.283037 & 0.281619 & 0.424909 & 0.349537 \\
0.2 & 0.256993 & 0.248221 & 0.464671 & 1.32405 \\
\hline \hline
\end{tabular}

Table. 5 Computation showing different values of $f^{\prime \prime}(0), \theta^{\prime}(0), C_{f}$ and $N u_{x}$ for different values of physical parameters.

\begin{tabular}{ccccc}
\hline \hline \multicolumn{5}{c}{ MWCNT $\mathrm{Gr}=0.5 \& \mathrm{Pr}=3$} \\
\hline \hline$\phi$ & $f^{\prime \prime}(\eta)$ & $-\theta^{\prime}(\eta)$ & $C_{f}$ & $-N u_{x}$ \\
\hline & & & & \\
0.0 & 0.760295 & 0.581940 & 0.760295 & 0.58194 \\
0.05 & 0.779139 & 0.467416 & 0.88574 & 0.504992 \\
0.1 & 0.773869 & 0.397550 & 1.00707 & 1.1564 \\
0.15 & 0.755237 & 0.346880 & 1.1338 & 0.430537 \\
0.2 & 0.727686 & 0.306812 & 1.27122 & 1.62422 \\
& & & & \\
\hline \hline
\end{tabular}

Table 6 Computation showing different values of $f^{\prime \prime}(0), \theta^{\prime}(0), C_{f}$ and $N u_{x}$ for different values of physical parameters.

\begin{tabular}{ccccc}
\hline \hline \multicolumn{5}{c}{ SWCNT $\mathrm{Gr}=1.0 \& \mathrm{Pr}=3$} \\
\hline \hline \multicolumn{1}{c}{$f^{\prime \prime}(\eta)$} & $-\theta^{\prime}(\eta)$ & $C_{f}$ & $-N u_{x}$ \\
\hline & & & & \\
0.0 & 1.107161 & 0.640803 & 1.10716 & 0.640803 \\
0.05 & 1.195485 & 0.513125 & 1.35905 & 0.554375 \\
0.1 & 1.234564 & 0.437194 & 1.6066 & 1.27171 \\
0.15 & 1.244549 & 0.382361 & 1.86838 & 0.474575 \\
0.2 & 1.233373 & 0.338922 & 2.15462 & 1.79421 \\
& & & & \\
\hline \hline
\end{tabular}

\section{CONCLUSION}

Some important findings of our paper are

1. Since the buoyancy parameter has a nature of the controlling the flow, the convection parameter $\mathrm{Gr}$ enhances the flow and velocity of the fluid.

2. The effect of $G r$ decreases on temperature as Gr increases, whereas the opposite nature observed in the case of effect of Prandlt number Pr.

3. Due to the characteristics of the velocity laminar flow local skin friction increases as increasing Grashof number $\mathrm{Gr}$ whereas opposite effects observed in the case of nusselt number.

\author{
NOMENCLATURE \\ $C_{p} \quad$ Specific heat \\ $C_{f}$ Friction co-efficient \\ $f$ Dimensionless stream function \\ $K$ Thermal conductivity \\ $\mathrm{Nu}_{x}$ Local Nusselt number \\ Pr Prandlt number \\ $q_{w}$ Wall heat flux \\ $\mathrm{Re}_{x}$ Local Reynolds number \\ $T$ Local fluid temperature \\ $T_{\infty} \quad$ Free stream temperature \\ $u$ Velocity along $\mathrm{x}$-axis \\ $u_{w}$ Velocity at wall \\ $v$ Velocity along y-axis \\ $x$ Distance along the plate \\ $y$ Distance normal to plate \\ $\alpha$ Thermal diffusivity \\ $\phi$ Volume friction of CNT \\ $\eta$ Similarity variable \\ $\mu$ Dynamical viscosity \\ $v$ Kinematic viscosity \\ $\rho$ Density \\ $\rho c$ Heat capacity of carbon nanotube \\ $\theta$ Dimensional temperature \\ Subscripts: \\ $n f$ Nanofluid \\ $f$ Base fluid \\ CNT Carbon - nanotube
}

\section{REFERENCES}

Hwang, K.S., Lee, J.H., Jang, S.P., 2007, "Buoyancy-Driven Heat Transfer of Water-Based $\mathrm{Al}_{2} \mathrm{O}_{3}$ Nanofluids in a Rectangular Cavity," Int. J. Heat and Mass Transfer 50, 4003-4010.

http://dx.doi.org/10.1016/j.ijheatmasstransfer.2007.01.037

Akbarinia, A., Behzadmehr, A., 2007, "Numerical Study of Laminar Mixed Convection of a Nanofluid in Horizontal Curved Tubes," Appl.Therm.Eng.27, 1327-1337.

https://doi.org/10.1016/j.applthermaleng.2006.10.034

Massimo, C., 2010, "Heat Transfer Features of Buoyancy Driven Nanofluids Inside Rectangular Enclosures Differentially Heated at the Sidewalls,'Int. J.

Therm. Sci., 49, 1536-1546.

https://doi.org/10.1016/j.ijthermalsci.2010.05.005

Makinde, O.D., Aziz, A., 2011, "Boundary Layer Flow of a Nanofluid Past a Stretching Sheet with a Convective Boundary Condition," Int. J. Therm.Sci.50, 1326-1332.

https://doi.org/10.1016/j.ijthermalsci.2010.05.005

Nasrin, R., Alim, M.A., Chamkha, A.J., 2012, "Buoyancy-Driven Heat Transfer of Water-A12O3 Nanofluid in a Closed Chamber: Effects of Solid Volume Fraction, Prandlt Number and Aspect Ratio," Int.J. Heat and Mass Transfer.55, 7355-7365.

https://doi.org/10.1016/j.ijheatmasstransfer.2012.08.011 
Njane, W.N.M., Makinde, O.D. 2013, "Combined Effects of Buoyancy Force and Navier Slip on Magnetohydrodynaic Flow of a Nanofluid Over a Convectively Heated Vertical Porous Plate," The Sci.W.J. 2013(2013)8 pages. http://dx.doi.org/10.115/2013/72643.

Yacob, N.A., Ishak, A., Nazar, R., Pop, I. 2013, "Mixed Convection Flow Adjacent to a Stretching Vertical Sheet in a Nanofluid, "J.Appl .mathematics 2013, 6 pages.

http://dx.doi.org/10.1155/2013/696191

Makinde, O.D., Khan, W.A., Khan, Z.H., 2013, "Buoyancy Effects on Magneto Hydrodynamic Stagnation Point Flow and Heat Transfer of a Nanofluid Past a Convectively Heated Stretching," Int.J.Heat Mass Transfer 62, 526-533.

https://doi.org/10.1016/j.ijheatmasstransfer.2013.03.049

Shariat, M., Moghari, R.M., Akbarinia, A., Rafee, A., Sajjadi, S.S. , 2014, "Impact of Nanoparticle Mean Diameter and Buoyancy Force on Laminar Mixed Convection Nanofluid Flow in an Elliptic Duct Employing Two Phase Mixture Model," Int.Comm. Heat Mass Transfer 50, 15-24. https://doi.org/10.1016/j.icheatmasstransfer.2013.11.003

Das, S., Jana, R. N., Makind, O. D. 2014, "MHD Boundary Layer Slip Flow and Heat Transfer of Nanofluid Past a Vertical Stretching Sheet with Nonuniform Heat Generation/Absorption," Int.J. Nanoscience 13, 12 pages. https://doi.org/10.1142/S0219581X14500197

Hayat, T., Ashraf, M. B., Shehzad, S. A., Alsaedi, A., 2015, "Mixed Convection Flow of Casson Nanofluid Over a Stretching Sheet with Convectively Heated Chemical Reaction and Heat Source/Sink," J. Appl Fluid Mechanics, 8, 803813.

https://doi.org/10.18869/acadpub.jafm.73.238.22995

Pal. D., Mandal, G., 2015, "Hydromagnetic Convective-Radiative Boundary Layer Flow of Nanofluids Induced by a Non-linear Vertical Stretching/Shrinking Sheet with Viscous-Ohmic Dissipation," powder technology. 279, 61-74.

https://doi.org/10.1016/j.powtec.2015.03.043

Hsiao, K.L., 2016, "Stagnation Electrical MHD Nanofluid Mixed Convection with Slip Boundary on a Stretching Sheet," Appl.Therm.Eng 98, 850-861.

https://doi.org/10.1016/j.applthermaleng.2015.12.138

Hayat, T., Hussain, M., Shehzad, S. A., Alsaedi, A., 2016, "Flow of a PowerLaw Nanofluid past a Vertical Stretching Sheet with a Convective Boundary Condition," J.Appl Mechanics and Technical Physics, 57, 173-179.

DOI: 10.1134/S0021894416010193

Aziz, A. 2009, “A Similarity Solution for Laminar Thermal Boundary Layer over a Flat Plate with a Convective Surface Boundary Condition," Comm.Nonlinea.Sci.NumerSimulat14, 1064-1068.

https://doi.org/10.1016/j.cnsns.2008.05.003

Nandeppanavar, M.M, Shakunthala.S, 2016, "Heat Transfer Analysis of Stagnation Point Over a Stretching Cylinder in a Suspension of Carbon Nanotube," J.Nanofluids 6, 1173-1180(8).

https://doi.org/10.1166/jon.2017.1416
Nandeppanavar, M.M., Shakunthala.S., 2016, "Blasius flow and Heat Transfer of a Nanofluid Due to Flat Plate," J.Nanofluids 5(5), 736-742(7).

https://doi.org/10.1166/jon.2016.1260

Ibrahim, W., Shankar, B., Nandeppanavar, M.M., 2013, "Magneto Hydrodynamic Stagnation Point Due to Flow and Heat Transfer towards a Stretching Sheet, "Int.J.Heat mass transfer, 56, 1-9.

https://doi.org/10.1007/s13204-013-0242-9.

Khan, W.A., Khan, V. Rahi, M., 2014, "Fluid Flow and Heat Transfer of Carbon Nanotubes along a Flat Plate with Navier Slip Boundary," Appl. Nanosci 4, 633-641.

https://doi.org/10.1007/s13204-013-0242-9

Angayarkanni, S.A., Philip, J., 2015," Review on Thermal Properties of Nanofluids: Recent Developments," Adv. Colloid Inter.Sci 225, 146-176. https://doi.org/10.1016/j.cis.2015.08.014

Devendiran, D.K., Amirtham, V.A., 2016, "A Review on Preparation, Characteristics Properties and Applications of Nanofluids;" Renewable and sustainable energy reviews 60, 21-40. https://doi.org/10.1016/j.rser.2016.01.055

Akbar, N. S., Khan, Z.H., Nadeem, S., (2014) "The Combined Effect of Slip and Convective Boundary Conditions on Stagnation-Point Flow of CNT Suspended Nanofluid Over a Stretching Sheet," Journal of Molecular Liquids .196, 21-25.

https://doi.org/10.1016/j.molliq.2014.03.006

Akbar.N.S, Khan. Z.H, Nadeem.S., 2014, “The Combined Effect of Slip and Convective Boundary Conditions on Stagnation-Point Flow of CNT Suspended Nanofluid Over a Stretching Sheet," J. Mole. Liquids 196, 21-25. https://doi.org/10.1016/j.molliq.2014.03.006

Makinde, O.D., Olanrewaju, P.O., 2010, "Buoyancy Effects on Thermal Boundary Layer Over a Vertical Plate with a Convective Surface Boundary Condition," J.Fluids Eng 132(4), 044502.

https://doi.org/10.1007/s11012-015-0122-3

Olanrewaju, P. O., Titiloye, E. O. , Adewale, S. O., Ajadi, D. A., 2012, “ Buoyancy Effects of Steady Laminar Boundary Layer Flow and Heat Transfer over a Permeable Flat Plate Immersed in a Uniform Free Stream with Convective Boundary Condition," American .J. Fluid Dynamics,2(3), 17-22. https://doi.org/10.5923/j.ajfd.20120203.02

Pantokratoras, A., 2015, "Buoyancy Effects on Thermal Boundary Layer over a Vertical Plate with a Convective Surface Boundary Condition: New Results," Meccanica 50, 1909-1914.

https://doi.org/10.1007/s11012-015-0122-3

Cortell, R., 2005, "Numerical Solutions of the Classical Blasius Flat-Plate Problem," Appl. Mathematics and Computation 170, 706-710. https://doi.org/10.1016/j.amc.2004.12.037

Makinde, O.D., 2009, “Analysis of Non-Newtonian Reactive Flow in a Cylindrical Pipe," J.Appl. Mathematics, 76, 034502. https://doi.org/10.1115/1.3086587 